[DOI: 10.24214/jecet.A.10.2.18491.]

Jaurnal of Environmental Science, Computer Science and Engineering \& Technology

An International Peer Review E-3 Journal of Sciences and Technology

Available online at www.jecet.org

Section A: Environmental Science

Research Article

\title{
Description and Significance of Plant Chemotypes*
}

\author{
H. Doğa GÜNGÖR and Esin OLUK* \\ Ege University, Faculty of Science, Department of Biology, Department of Botany \\ 35100, Bornova-Izmir/TURKEY
}

Received: 10 April 2021; Revised: 17 April 2021; Accepted: 08 May 2021

\begin{abstract}
There may be a difference between individuals belonging to the same plant species or even subspecies or varieties in a population, in terms of the amount and varieties of secondary metabolites they produce. Such individuals, who are systematically in the same category and differ in their chemical properties, are called chemotypes. In this study, the factors that are effective in the formation of chemotypes in plants, the naming of the formed chemotypes, the main compounds that vary and the examples of chemotypes were tried to be examined.
\end{abstract}

Keywords: Chemotype, secondary metabolite, chemotaxonomy, herbivore, ecosystem

\section{INTRODUCTION}

Plants in a terrestrial ecosystem, are the main food sources for herbivorous and omnivorous living things. Since plants mostly cling to the earth and do not move in the usual sense, they developed various defense mechanisms to protect themselves in the evolutionary process ${ }^{[1]}$. These mechanisms can be occurred as restrictive defense of a certain group of plant-fed consumers [2], blowback potential consumers ${ }^{[3]}$, compensating for damage caused by herbivores ${ }^{[4,5]}$, relationships with carnivorous or mutualistic creatures ${ }^{[6,7]}$. There are a wide range of structures and products such as trichomas, stone cells, defense proteins and secondary metabolites which participates in these mechanisms allowing them to be processed. Of these, secondary metabolites are usually produced to offend the consumers (herbivores, predators etc.), to minimize the amount of tissue that can be eaten, and thus harming the consumer ${ }^{[8]}$. Thus, it is an expected issue that secondary metabolites differ in quantity and variety between species in terms of adaptation of the plant to the region where is located. However, chemical 
polymorphism can also be found among individuals within the population of some species, which is spreading in a certain region. Due to this variety of species that will not interfere with intra-fertilization, these individuals are defined as chemotypes, to distinguish them from others ${ }^{[9]}$. Although it is noted that chemotypes usually occur in members of Lamiaceae family, and especially in terms of essential oils ${ }^{[10-12]}$, new studies today have also determined that chemotypes are formed in species belonging to different families and in terms of different compounds ${ }^{[13,14]}$. However, due to the inadequate analytical techniques in the study of non-volatile secondary metabolites ${ }^{[15]}$, it is seen that such studies are still very few. In this review article, the factors that are effective in the formation of chemotypes in plants, the naming of the formed chemotypes, the relationship of chemotypes with each other and the environment (biotic+abiotic factors) and variable major secondary compounds are discussed in the light of current studies.

\section{DESCRIPTION, TERMINOLOGY, NOMENCLATURE}

"Chemotype: Chemically characteristic parts of a population consisting of morphologically indistinguishable individuals"; this definition was first made in 1968 by Dr. Rolf Santesson and his son Johan Santesson ${ }^{[16]}$. This diversity may occur in different parts of the plant ${ }^{[17]}$ or in the same part, but at different developmental stages (such as vegetative or generative) ${ }^{[18]}$ or depending on the age of the plant ${ }^{[19]}$. In addition, plants can produce chemotypes by producing different amounts of the same compound [21], as well as by producing a secondary metabolite (major compound) different from other individuals in the population ${ }^{[14,20] .}$ Again, chemotypes can occur as pure chemotypes defined by the predominant component difference covering more than $50 \%$ of the entire composition, and mixed chemotypes defined by a difference of 2-3 components of less than $50 \%$ of the overall composition $^{[22,23]}$.

On the other hand, the diversity in terms of the quantity of active compounds is called $\alpha$-chemodiversity and the diversity in terms of quality is called $\beta$-chemodiversity [24]. The naming (or classification) of chemotypes is usually based on the compound they differ from. Ex. Cinnamomum camphora (L.) Presl plant has 5 chemotypes, isoborneol-type, camphora-type, cineole-type, linalool-type and borneol-type with the full name of the compounds [25]. In Barbarea vulgaris, the abbreviation of the compound is used when naming the chemotypes; Auch as BAR-tip (the dominant compound glucobarbarin) and NAS-tip (the dominant compound gluconasturtiin) ${ }^{[26] .}$

Sometimes it is seen that naming is made based on the number of chemotypes occurring in the population: such as chemotype 1 and chemotype 2. Ex. Two chemotypes have been identified in the plant Tephrosia vogelii, and individuals with deguelin as the major rotenoid were identified as chemotype 1, and individuals without deguelin but with flavanones and flavones were identified as chemotype 2 [14]. However, as can be seen from these examples, it can be said that there are contradictions and deficiencies in the naming (classification) of chemotypes. Polatoğlu (2013) elaborated on the problematic issues on this subject in a study he conducted ${ }^{[15]}$.In the usual classification of chemotypes to date, first the names of the plant species and subspecies are written, then "ct." abbreviation is added, followed by the distinctive chemical name of the plant. In another method, the species and subspecies names of the plant are written first, then the name of the dominant metabolite in lowercase letters in parentheses, followed by CT. is added. CT./ct. abbreviations and the name of the active compound are not written in italics. Polatoğlu suggested in his article that a new initiative should be initiated to determine a systematic method, naming system, and a precise definition in the evaluation of chemotypes ${ }^{[15]}$. 
According to the researcher, when naming a chemotype, in addition to the original compound it has, the initial letter of the author's name, the region where it was collected, the frequency of occurrence $(\%)$ and the number of samples above the frequency (as the upper value) will be enlightening to both researchers and breeders interested in the subject. To organize such an example as follows it may be possible: For example, there are six chemotypes of Thymus vulgaris L. ${ }^{[27,28] .}$ One of them is "thymoltip"; namely "Thymus vulgaris L. thymol CT". If Esin OLUK determined this chemotype, the plant was collected from Izmir, the frequency of its presence in the population (fr.) is $70 \%$ and the sample number is 124 .

According to the proposed new regulation, we will now have to write this chemotype as: Thymus vulgaris L. (thymol CT O İzmir fr. $70^{124}$ ). As can be seen from this example, it is very clear that in this new approach in parentheses, which we can call "trinominal nomenclature" [15], there is more information about chemotype and it will be more beneficial to the relevant audience.

\section{CHEMOTYPE FORMATION, SIGNIFICANCE AND SOME CHEMOTYPE EXAMPLES}

Chemotypes can occur between individuals of the same species as well as individuals of subspecies or varieties [29]. Various factors have a collective effect on the formation of chemotypes, as has been

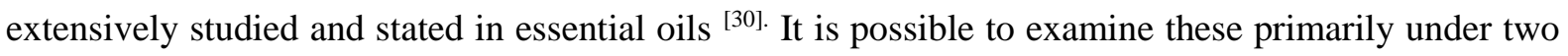
main headings as external and internal factors. Among the external factors, which are also defined as environmental regulatory factors, light, temperature, precipitation and soil act as abiotic factors ${ }^{[31]}$.

Apart from these, geographical factors such as altitude and distance to the sea also cause chemical variation of the plants together with the climate of the environment ${ }^{[32] . ~ A m o n g ~ t h e ~ b i o t i c ~ e l e m e n t s, ~}$ particular attention is paid to herbivores ${ }^{[33]}$ and pathogens ${ }^{[34] ;}$ these elements play an important role in the formation of chemotypes by stimulating the plants' defense mechanisms. When we say intrinsic factors, first of all, the effects of related biochemical pathways and changes in the enzymes that work in these pathways are understood ${ }^{[35] .}$

More generally, in order to talk about the formation of a chemotype, minor genetic and epigenetic changes must occur in the plant and the resulting response (chemical diversity) must be passed on to future generations ${ }^{[36]}$. As a matter of fact, recent studies have shown that the composition variations between chemotypes are caused by genetic composition variations ${ }^{[37]}$ and that a change in the expression of a single allele or gene in terms of genetic changes is sufficient to change the knowledge of how and at what rate the related compounds will be synthesized [38]. On the other hand, since secondary metabolites do not participate in primary metabolism, mutations that occur during the matching and coding of genes involved in secondary metabolite synthesis do not affect the plant's functionality; therefore, there is no morphological differentiation.

However, the opposite situation is present. The pathways required for the functioning of secondary metabolism require morphological pathways. In other words, morphological pathways are prerequisites for secondary metabolism pathways; that is, secondary metabolic pathways cannot start working without morphological differentiation; eg. The lack of latex formation in the poppy plant (Papaver somniferum) without laticifers ${ }^{[39]}$ or the dimeric indole alkaloids in Catharanthus roseus need idioblast formation for biosynthesis ${ }^{[40] \text {. }}$

Plant chemotypes are important in different areas. The most prominent of these is the pharmaceutical and cosmetic industry. In one study, it has been emphasized that the prominent compounds (pinene and 
sabinen) of a chemotype (chemotype A) of Murraya koenigii (L.) Spreng. (curry tree) plant are valuable for the flavor industry, so this chemotype is ideal for commercialization [41]. Likewise, the Thymus vulgaris L. (thyme) plant was included in the European Pharmacopoeia (EPh 7 th) ${ }^{[42]}$ due to its valuable aromatic compounds used for both spice and medicinal purposes. The plant has six chemotypes: thymol, carvacrol, linalool, geraniol, $\alpha$-terpineol, trans-thujan-4-ol / terpinen-4-ol, whose entire aboveground part (Thymi herba) is rich in essential oils ( $<1.2 \%$ according to $\mathrm{EPh} 7$ th rationales). ${ }^{[43-45] .} \mathrm{On}$ the other hand, the plant Tephrosia vogelii has been reported to be widely used as a botanical pesticide in East Africa (Tanzania, Kenya, and Malawi) due to the entomotoxic rotenoids it produces ${ }^{[13] .}$ In this study ${ }^{[13]}$, two chemotypes of the plant were determined and it was stated that chemotype 1 , which is rich in rotenoid (deguelin), is more effective on insects than chemotype 2, which is rich in flavanone and flavone.

\section{CONCLUSION}

Plants respond to biotic and abiotic environmental changes or attacks they are exposed to by changing their physical and chemical properties (plasticity). Their chemical changes are supported by driving their secondary metabolism. Secondary metabolites produced in this way are generally considered as structures that constitute the plant's defense mechanism and therefore, contrary to their names, have an extremely primary role in plant life.

Depending on the severity and duration of the changes the plants are exposed to, the emergence, variety and permanence of these products increase. It is inevitable that the secondary metabolite production of individuals in a population fluctuates even during the day depending on external environmental conditions. Therefore, depending on the conditions the plant is harvested for analysis, different secondary metabolites can be detected instantly.

As it is understood from the studies carried out, in order to qualify individuals with different chemical profiles emerging in the species, subspecies or varieties of a plant as a chemotype, it must definitely be determined that the relevant character is genetically hosted and passed on to the next generations. On the other hand, suggestions for correcting the mistakes that cause contradictions in the naming of chemotypes seem to be beneficial.

Since research on plants for the pharmaceutical or cosmetic industry focuses on issues such as obtaining, increasing and processing secondary metabolites, not only the systematic identity of the organism to be studied but also its chemical identity is important. Therefore, chemotypes are becoming an increasing focus of research. The demonstration that plant chemotypes can be used in biological control is remarkable because such plants are only effective on target organisms (pests) and do not cause any damage to beneficial ecosystem services.

\section{REFERENCES}

1. Juan Nunez-farfan, Juan Fornoni, Pedro Luis Valverde: The Evolution of Resistance and Tolerance to Herbivores, 2007

2. A. Kessler, R. Halitschke, I. T. Baldwin: Silencing the Jasmonate Cascade: Induced Plant Defenses and Insect Populations, 2004 
3. C. M. De Moraes, M. C. Mescher, J. H. Tumlinson: Catepillar-induced nocturnal plant volatiles repel conspesific females, 2001

4. J. P. Rosenthal, S. C. Welter: Tolerance to Herbivory by a Stemboring Catepillar in Architecturally Distict Maizes and Wild Relatives, 1995

5. S. Y. Strauss, A. A. Agrawal: The Ecology and Evolution of Plant Tolerance to Herbivoriy, 1999

6. M. Heil, R. Karban: Expalining Evolution of Plant Communication by Airborne Signals, 2010

7. C. Kost, M. Heil: Herbivore-induced Plant Volatiles Induce an Indirect Defence in Neighboring Plants, 2006

8. J. M. Stam, A. Kroes, Y. Li, R. Gols: Plant Interactions with Multiple Insect Herbivores; From Community to Genes, 2014

9. K. Keefover-Ring, J. D. Thonpson and Y. B. Linhart, "Beyond Six Scents: Defining a Seventh Thymus vulgaris Chemotype New to Southern France by Ethanol Extraction," Flavour and Fragrance Journal, Vol. 24 No. 3, 2009, pp. 117-122. doi:10.1002/ffj.1921

10. L.R.Salgueiro, R. Vila, X. Tomas, S. Canigueral, J. Paiva, A.P. da Chuna, T. Adzet, Essential oil composition and variability of Thymus lotocephalus and Thymus mourae. Biochemical Systematics and Ecology, 2000, 28, 457-470.

11. V. Slavkovska, R. Jancic, S. Bojovic, S. Milosavljevic, D. Djokovic, Variability of essential oils of Satureja montana L and Satureja kitaibelii Wierzb. ex Heuff. from the central part of the Balkan peninsula. Phytochemistry, 2001,57, 71-76

12. A. Angioni, A. Barra , V. Coroneo, S. Dessi, P.Cabras, Seasonal, plant part chemical variability and antifungal activity investigation of Lavandula stoechas L ssp stoechas essential oils. Journal of Agricultural and Food Chemistry, 2006, 54, 4364-4370.

13. Angela G. Mkindi, Yolice Tembo, Ernest R. Mbega , Beth Medvecky, Amy KendalSmith, Iain W. Farrell, Patrick A. Ndakidemi, Steven R. Belmain and Philip C. Stevenson, Phytochemical Analysis of Tephrosia vogelii across East Africa Reveals Three Chemotypes that Influence Its Use as a Pesticidal Plant, Plants 2019, 8, 597; doi:10.3390/plants8120597

14. Lisa Johanna Tewes \& Caroline Müller, Interactions of Bunias orientalis plant chemotypes and fungal pathogens with diferent host specifcity in vivo and in vitro, Scientific Reports , 2020 10:10750 | https://doi.org/10.1038/s41598-020-67600-7

15. Kaan Polatoğlu: "Chemotypes" A Fact that should not be Ignored in Natural Product Studies, 2013

16. R. Santesson, Svensk Some aspects of lichen taxonomy, Naturvetenskap, 1968, 21, 176184

17. S.S.Cheng, H.Y.Lin , S.T.Chang, Chemical composition and antifungal activity of essential oils from different tissues of Japanese Cedar (Cryptomeria japonica). Journal of Agricultural and Food Chemistry, 2005, 53, 614-619. 
18. M. Hudaib, E. Speroni, A.M.Di Pietra, V. Cavrini, GC/MS evaluation of thyme (Thymus vulgaris L.) oil composition and variation during the vegetative cycle. Journal of Pharmaceutical and Biomedical Analysis, 2002, 29, 691-700.

19. A.C. Atti-Santos, M. Rossato, G.F. Pauletti, L.D. Rota, J.C. Rech, M.R. Pansera, F. Agostini, L.A. Serafini \& P. Moyna, Physico-chemical evaluation of Rosmarinus officinalis L. essential oils. Brazilian Archives of Biology and Technology,2005, 48, 10351039.

20. Yolande Despinasse, Sandrine Moja, Catherine Soler, Frédéric Jullien, Bernard Pasquier , Jean-Marie Bessière, Camille Noûs, Sylvie Baudino and Florence Nicolè, Structure of the Chemical and Genetic Diversity of the True Lavender over Its Natural Range, Plants 2020, 9, 1640; doi:10.3390/plants9121640

21. Merajuddin Khan, Shams T. Khan, Mujeeb Khan, Ahmad A. Mousa, Adeem Mahmood and Hamad Z. Alkhathlan, Chemical diversity in leaf and stem essential oils of Origanum vulgare L. and their efects on microbicidal activities, Khan et al. AMB Expr,2019, 9:176 https://doi.org/10.1186/s13568-019-0893-3

22. Forsén, K. Begleitstoffe in verschiedenen chemotypen von Chrysanthemum vulgare II. Reine trans-Chrysanthenylacetat-Type. Farmaseuttinen Aikakauslehti, 1974, 83, 9-17.

23. I. Ognyanov, F.T.B. Min, M. Todorova, L. Kuleva, Chemotypes in some Bulgarian populations of Chrysanthemum vulgare (L.). Bernh. Comptes rendus de l'Académie bulgare des Sciences, 1992, 4, 29-31

24. Ben D. Moore, Rose L. Andrew , Carsten Kulheim and William J. Foley, Explaining intraspecific diversity in plant secondary metabolites in an ecological context, New Phytologist,2014, 201: 733-750 doi: 10.1111/nph.12526

25. Xiali Guo, MengCui, Min Deng, Xingxing Liu, Xueyong Huang, XingleiZhang \& Liping Luo1, Molecular differentiation of five Cinnamomum camphora chemotypes using desorption atmospheric pressure chemical ionization mass spectrometry of raw leaves, ScienTiFic REPOrts | 7:46579 | DOI: 10.1038/srep46579

26. Hanneke van Leur \& Louise E. M. Vet \& Wim H. van der Putten \& Nicole M. van Dam, Barbarea vulgaris Glucosinolate Phenotypes Differentially Affect Performance and Preference of Two Different Species of Lepidopteran Herbivores, J Chem Ecol, 2008, 34:121-131, (doi:10.1007/s10886-007-9424-9)

27. R.K.Morgan, Chemotypic characteristics of Thymus vulgaris L. in Central Otago, New Zealand. J. Biogeogr. 1989, 16, 483-491.

28. A. Wesołowska, D. Jadczak, Comparison of the chemical composition of essential oils isolated from two thyme (Thymus vulgaris L.) cultivars. Not. Bot. Horti Agrobot. ClujNapoca 2019, 47, 829-835.

29. A.E.Desjardins, Natural product chemistry meets genetics: when is a genotype a chemotype? J. Agric. Food Chem.2008, 56, 7587-7592.

30. A. Karimi , A. Krähmer, N. Herwig, H. Schulz, J. Hadian and T. Meiners, Variation of Secondary Metabolite Profile of Zataria multiflora Boiss. Populations Linked to 
Geographic, Climatic, and Edaphic Factors. Front. Plant Sci.2020, 11:969. doi: 10.3389/fpls.2020.00969

31. Andrea Barra, Factors Affecting Chemical Variability of Essential Oils: a Review of Recent Developments, Natural Product Communications,2009, 4 (8): 1147-1154.

32. T. Züst, C. Heichinger, U. Grossniklaus, R. Harrington, D. J. Kliebenstein, L. A. Turnbull: Natural Enemies Grive Geographic Variation in Plant Defenses, 2012

33. S. Kleine \& C. Müller, Intraspecifc plant chemical diversity and its efects on herbivores. Oecologia, 2011,166, 175-186. https://doi. org/10.1007/s00442-010-1827-6.

34. I. Ahuja, R. Kissen \& A.M.Bones, Phytoalexins in defense against pathogens. Trends Plant Sci.2012, 17, 73-90. https://doi.org/10.1016/j. tplants.2011.11.002.

35. F. Chen, D. Tholl, J. Bohlmann, E. Pichersky: The Family of Terpene Synthases in Plants; a Mid-size Family of Genes for Specialized Metabolism that is Highly Diversified Throughout the Kingdom, 2011

36. Alexander V. Kutchin, DSc, Lyudmila N. Shishkina, DSc, Larissa I. Weisfeld, PhD, Chemistry and Technology of Plant Substances: Chemical and Biochemical Aspects, Apple Academic Press Inc., 2017

37. P. Liu, L. Wang, Q. Du, H. Du, Chemotype classification and biomarker screening of male Eucommia ulmoides Oliv. Flower core collections using UPLC-QTOF/MS-based nontargeted metabolomics. PeerJ,2020, 8:e9786 DOI 10.7717/peerj.9786

38. Amanda Padovan, Andras Keszei, William J Foley and Carsten Külheim, Differences in gene expression within a striking phenotypic mosaic Eucalyptus tree that varies in susceptibility to herbivory, BMC Plant Biology 2013, 13:29, http://www. Biomedcentral. com/1471-2229/13/29

39. Craig L. Nessler, Randy D. Allen, And Samuel Galewsky, Identification and Characterization of Latex-Specific Proteins in Opium Poppy, Plant Physiol.1985, 79, 499504 0032-0889/85/79/0499/06/\$01.00/0

40. Benoit St-Pierre, Felipe A. Vazquez-Flota,1 and Vincenzo De Luca, Multicellular Compartmentation of Catharanthus roseus Alkaloid Biosynthesis Predicts Intercellular Translocation of a Pathway Intermediate, The Plant Cell,1999,11, 887-900.

41. R.S.Verma, R.C.Padalia, V. Arya, A. Chauhan, Aroma profiles of the curry leaf, Murraya koenigii (L.) Spreng. chemotypes: Variability in north India during the year. Ind Crops Prod. 2012; 36(1): 343-348.

42. European Pharmacopoeia, 7th ed.; European Directorate for the Quality of Medicines and Health Care (EDQM), Council of Europe: Strasbourg, France, 2010.

43. R.K.Morgan, Chemotypic characteristics of Thymus vulgaris L. in Central Otago, New Zealand. J. Biogeogr. 1989, 16, 483-491.

44. A. Wesołowska, D. Jadczak, Comparison of the chemical composition of essential oils isolated from two thyme (Thymus vulgaris L.) cultivars. Not. Bot. Horti Agrobot. ClujNapoca 2019, 47, 829-835. 
45. Olga Kosakowska, Katarzyna B aczek, Jarosław L. Przybył, Anna Pawełczak, Katarzyna

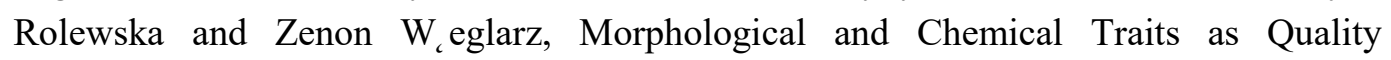
Determinants of Common Thyme (Thymus vulgaris L.), on the Example of 'Standard Winter' Cultivar, Agronomy 2020, 10, 909; doi:10.3390/agronomy10060909

\section{* Corresponding Author: Dr. Esin OLUK*, Ph.D}

*Ege University, Faculty of Science, Department of Biology, Department of Botany 35100, Bornova-Izmir/TURKEY

**This study was compiled from H. Doğa GÜNGÖR's diploma thesis Online date of publication: 10.05 .2021 